\title{
Synthesis and Characterization of CN Thin Films Produced by DC-Pulsed Sputtering in an $\mathrm{CH}_{3} \mathrm{CH}_{2} \mathrm{OH}-$ N2 Atmosphere
}

Marcos Crescencio González Domínguez ${ }^{*}, 1$, Pedro Guillermo Reyes Romero ${ }^{1}$, Aarón Gómez Díaz ${ }^{1}$, Horacio Martínez Valencia², Víctor Hugo Castrejón Sanchez ${ }^{3}$

${ }^{1}$ Universidad Autónoma del Estado de México, Laboratorio de Física Avanzada, Facultad de Ciencias, Toluca, 50000, México

${ }^{2}$ Universidad Nacional Autónoma de México, Laboratorio de Espectroscopía, Instituto de Ciencias Fisicas, Cuernavaca, 48, México

${ }^{3}$ Tecnologico de Estudios Superiores de Jocotitlán, Jocotitlán, México.

\begin{tabular}{l} 
A R T I C L E I N F O \\
\hline Article history: \\
Received: 30 November, 2021 \\
Accepted: 31 January, 2022 \\
Online: 10 February, 2022 \\
\hline Keywords: \\
CN $_{x}$ \\
Sputtering \\
Raman \\
SEM \\
AFM \\
OES
\end{tabular}

\begin{abstract}
A B S T R A C T
This paper reports on the successful deposition of amorphous carbon nitride thin films (a$\mathrm{CN}_{x}$ ). Samples were deposited using a DC-pulsed sputtering technique in $\mathrm{CH}_{3} \mathrm{CH}_{2} \mathrm{OH}-\mathrm{N}_{2}$ atmosphere at constant pressure (1 Torr). Raman spectra were collected to investigate the bonding structure of the deposed thin films, while scanning electron microscopy (SEM) and atomic force microscopy (AFM) were used to study thin-film surface morphology. Plasma characterization was performed during the deposition process using optical emission spectroscopy $(O E S)$, and the influence of the deposition process parameters on the chemical fragmentation of species present in the plasma was determined. Raman results were typical for a-CN $\mathrm{N}_{x}$ films, and SEM analysis showed that carbon clusters deposited onto the Cu substrate form a non-homogeneous surface. The morphology observed by AFM indicated that the thin films grow as islands, which corroborate the generation of amorphous structures grown on the $\mathrm{Cu}$ surface. OES spectra verified the existence of $C N$ radicals within the $\mathrm{CH}_{3} \mathrm{CH}_{2} \mathrm{OH} / \mathrm{N}_{2}$ plasma during thin-film deposition.
\end{abstract}

\section{Introduction}

The miniaturization demands in the electronic industry required development of new materials that allow the creation of these miniature devices. A good candidate material is carbon, which has a wide variety of allotropic forms with interesting physical and chemical properties. Although the properties of diamond and graphite have been extensively investigated, there are other allotropic forms (fullerenes) that are of great interest today. Since its discovery, carbon nitride $(\mathrm{CN})$ has aroused great interest in theoretical [1] and experimental studies, given its physical and chemical properties. Carbon nitrides have attracted attention owing to their potential applications in anti-corrosion photoelectrochemical technology [2], photo-degradation [3], and photo-catalysis [4, 5], which can be used in optoelectronics [6] and the manufacture of biosensors [7, 8]. From an experimental point of view, the most important material successes have been in the synthesis of carbon nitrides in the form of thin films by chemical and physical deposition of vapor. Among the physical

${ }^{*}$ Corresponding Author: Marcos Crescencio González Domínguez,

kenny.sxe4@gmail.com

www.astesj.com

https://dx.doi.org/10.25046/aj070106 deposition methods, the use of plasmas [9], especially the sputtering method [10], has been successfully implemented for deposition of carbon nitrides. Recently, a hybrid coating process that combines RF and DC sputtering systems has been successfully used: DC magnetron or DC-pulsed discharge [11, 12]. The advantages of these hybrid coating processes are that the various deposition parameters (e.g., working pressure, sputtering power, current, substrate bias voltage, and target material) can be adjusted separately to produce films with excellent mechanical and tribological properties.

The physical properties of carbon-based films depend upon different forms of hybrid bonds of the carbon atom: $\mathrm{sp}^{1}, \mathrm{sp}^{2}$, and $\mathrm{sp}^{3}$. The incorporation of nitrogen into the system enables the formation of different kinds of carbon configurations, including $\mathrm{sp}^{3}$ (tetrahedral bond), $\mathrm{sp}^{2}$ (triple bond) and $\mathrm{C}=\mathrm{N}$ and $\mathrm{N}=\mathrm{C}$-type chains. These configurations improve the mechanical and physical properties of $\mathrm{CN}_{x}$ compounds, increasing the application range of the films [13]. To the best of our knowledge, there are no publications in the literature reporting attempts to synthesize $\mathrm{C}-\mathrm{N}$ compounds by $\mathrm{CH}_{3} \mathrm{CH}_{2} \mathrm{OH}-\mathrm{N}_{2}$ DC-pulsed sputtering. Even more 
significantly, there still exist various unanswered queries about how the growth process impacts the resulting structure in amorphous $\mathrm{CN}\left(\mathrm{a}-\mathrm{CN}_{x}\right)$ films. The purpose of this article is to investigate the morphological and microstructural properties of a$\mathrm{CN}_{x}$ films deposited by DC-pulsed sputtering in a $\mathrm{CH}_{3} \mathrm{CH}_{2} \mathrm{OH}-\mathrm{N}_{2}$ plasma mixture. Characterization of the bond structure of the thin films was performed by Raman spectroscopy, and their morphology and microstructure were investigated using scanning electron microscopy (SEM) and atomic force microscopy (AFM). Plasma characterization during thin-film deposition was also carried out using optical emission spectroscopy (OES), and these findings are correlated to variations in microstructure and morphology of the thin films.

\section{Materials and Method}

Reactive sputtering is a suitable coating technique for the preparation of thin films. The pulsed DC sputtering deposition system used in this work (Figure 1) consists of a cylindrical stainless-steel chamber (33-cm long, 20-cm radius, and a volume of $1.04 \times 10^{3} \mathrm{~cm}^{3}$ ) and two mobile $\mathrm{Cu}$ electrodes $(5-\mathrm{cm}$ in diameters) placed in the center of the vacuum chamber with a separation space of $20 \mathrm{~mm}$. The power supply consisted of Pinnacle Plus+ generators, which delivered DC power in a pulsing configuration to enable reactive sputtering. Pirani pressure sensors (MKS, model $103170027 \mathrm{SH}$ ) were used to determine the total pressure in the chamber, and a flowmeter (Matheson Tri. Gas FM-1050) was used to regulate the gas flow within the system. An ocean optics spectrometer monitored the optical emission spectra generated within the discharge and the chamber vacuum was formed using a mechanical pump (Varian DS302). The background and working pressure of the vacuum chamber were 2 $\times 10^{-2}$ and 1 Torr, respectively.

High-purity $\mathrm{CH}_{3} \mathrm{CH}_{2} \mathrm{OH}(99.9 \%)$ was used as the carbon precursor, and high-purity nitrogen $(99.9 \%)$ was used both as the sputtering ion source, which bombards the target, and as the nitrogen species, which is introduced into the thin films with carbon ions. The relation of the mixture was $20 \%-\mathrm{CH}_{3} \mathrm{CH}_{2} \mathrm{OH}$ to $80 \%-\mathrm{N}_{2}$. To generate plasma, the vacuum chamber is first evacuated with a mechanical pump until a base pressure of $2 \times$ $10^{-2}$ Torr is reached; next, it is filled with $\mathrm{CH}_{3} \mathrm{CH}_{2} \mathrm{OH}-\mathrm{N}_{2}$ mixture gas and discharge is generated by applying a pulsed current (300 $\mathrm{mA}$ at $450 \mathrm{~V}$ ) between two electrodes. Then, the $\mathrm{CH}_{3} \mathrm{CH}_{2} \mathrm{OH}-\mathrm{N}_{2}$ mixture gas is ionized and accelerated by the electrical field produced by the electrodes, forming an energetic ion beam that provides both sputtering ions and reacting nitrogen and carbon precursors. A Cu disk was used as a substrate for the growth of CNx films. Pulsed discharge was performed for 1 hour. The intention of growing $\mathrm{CNx}$ films on the surface of $\mathrm{Cu}$

The bond structure and microstructure of the thin films was investigated using Raman spectroscopy (micro-Raman, LabRam HR 800 system). Raman measurements were recorded using a $\mathrm{He}-\mathrm{Ne}$ laser, which was focused using a 50X lens. During the measurements, 60 recoded data were collected every $60 \mathrm{~s}$. SEM (Jeol IT-100 coupled to a Bruker X-Ray microscope) and AFM (EasyScan 2 Flex AFM) were used to determine the thin-film morphology. The SEM microscope was operated in high voltage mode with an accelerating voltage of $20 \mathrm{kV}$. SEM studies were carried out on the electrolytic $\mathrm{Cu}(99.99 \%)$ substrate to observe the formation of attached carbon structures and thus corroborate their existence.

To characterize the plasma during film deposition, the species generated within the plasma discharge was observed by optical emission spectroscopy (OES). An ocean optics HR 4000CG-UVNIR spectrometer was used, and spectra were observed in a wavelength range of 200 to $850 \mathrm{~nm}$, with a resolution of $0.75-\mathrm{nm}$ FWHM.

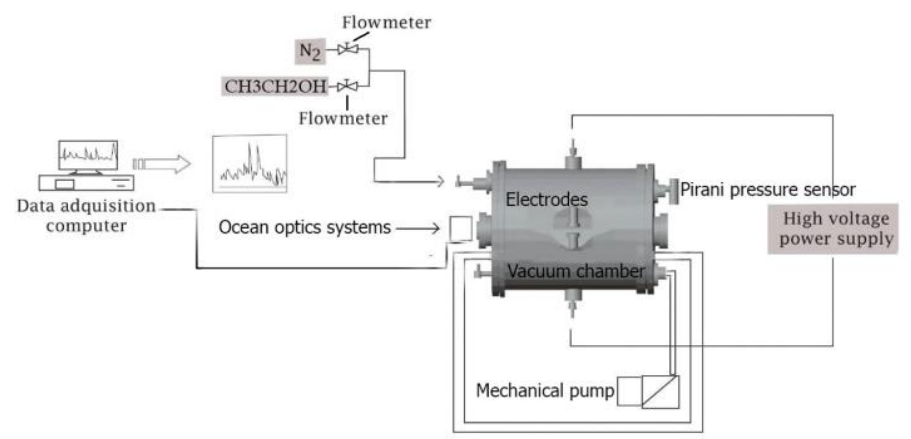

Figure 1: Experimental apparatus

\section{Results and Discussion}

\subsection{Raman spectroscopy}

Raman spectroscopy is commonly used to analyze the bond structure of carbon-related materials. Visible Raman spectroscopy is 50 to 230 times more sensitive to $\mathrm{sp}^{2}$ sites because $\pi$ electrons are preferentially excited with visible photons [12]. Thus, the Raman spectra obtained for the deposited $\mathrm{CN}_{\mathrm{x}}$ films provided double-link information, in addition to indication of changes in film microstructure.

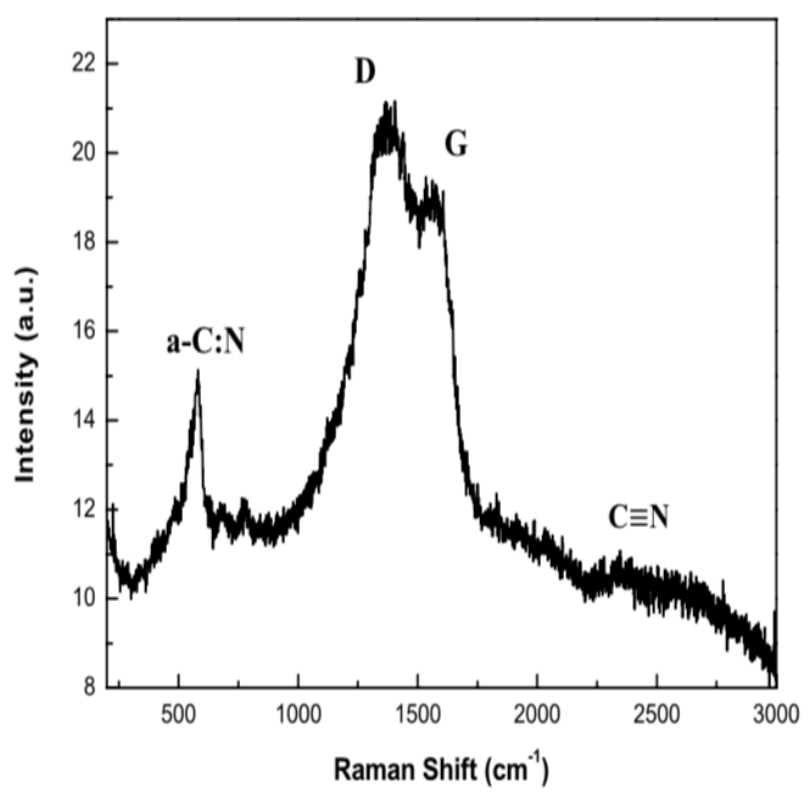

Figure 2: Raman spectra of thin $\mathrm{CN}_{\mathrm{x}}$ deposited by pulsed discharge at a pressure of 1 Torr.

Figure 2 shows Raman spectra for $\mathrm{CN}_{\mathrm{x}}$ films deposited onto $\mathrm{Cu}$ at $300 \mathrm{~mA}, 550 \mathrm{~V}$ and $120 \mathrm{~W}$ at a working pressure of 1 Torr. Raman bands appear at 692, 1,362 (D peak), 1,588 (G peak), and $2,250 \mathrm{~cm}^{-1}$ [14]. The $692 \mathrm{~cm}^{-1}$ band is characteristic of $\mathrm{CN}$ films 
deposited under the influence of a reactive gas. This band may also appear owing to structural disorder in the film. The $G$ peak arises from stretching vibrations at all $\mathrm{sp}^{2}$ sites, both in olefinic chains and in aromatic rings, while the existence of the D peak is associated with breathing vibrations in the aromatic rings. These peaks, therefore, indicate the presence of distorted-ring structure, or the lack of coherence between adjacent planes of graphite-like structures $[15,16]$. This is due to the disorder in the link angles, despite the graphite-like micro-domains induced by the binding of $\mathrm{sp}^{3}$ carbon atoms or the finite size of the $\mathrm{sp}^{2}$ micro-domains.

The $\mathrm{D}$ peak is only related to the presence of aromatic rings. The D peak arises in materials that exhibit formations of small clouds or clusters organized into such rings (graphite clusters) [17]. The band centered at about $2250 \mathrm{~cm}^{-1}$ is due to the stretching vibration of a $\mathrm{C}-\mathrm{N}$ triple bond, suggesting that the $\mathrm{C}$ and $\mathrm{N}$ atoms are chemically bonded in the film. The position of the $\mathrm{D}$ and $\mathrm{G}$ peaks, together with their widths and the relationship between their inetnsities $\left(I_{D} / I_{G}\right)$ provide valuable information concerning the deposited films.

The position of the $G$ peak is shifted toward higher energies as a result of the current used within our system $(300 \mathrm{~mA})$. This current value guarantees an increase in the system temperature. The position of the $\mathrm{G}$ peak, independent of the composition of the film or the growth method, is related to the vibrational energy of the present bonds. Therefore, the shift toward high frequencies is due to a decrease in $\mathrm{sp}^{3}$ bonds and an increase in $\mathrm{sp}^{2}$ links [18]. This indicates that a conversion of $\mathrm{sp}^{3}$ to $\mathrm{sp}^{2}$ bonds occurred in the a- $\mathrm{CN}_{x}$ films due to the increase in temperature. This conversion process could form graphite domains with larger size and/or a number of $\mathrm{sp}^{2}$ clusters, eventually leading to graphitization.

The Raman shift of the D peak at high frequencies suggests a densification of $\mathrm{sp}^{2}$-ringed structures in the atomic network, which also leads to increased $\mathrm{sp}^{2}$-link content [15]. On the other hand, $I_{D} / I_{G}=1.11$, which suggests that $\mathrm{C} \mathrm{sp}{ }^{2}$ are more likely to form $\mathrm{C}=\mathrm{C}$ and/or $\mathrm{C}=\mathrm{N}$ bonds in rings and less likely to form $\mathrm{C}=\mathrm{C}$ and/or $\mathrm{C}=\mathrm{N}$ bonds in chains. Additionally, the $I_{D} / I_{G}$ value indicates the growth of graphite domains or an increase in their number [19-21], i.e., graphitization by heating with an increase in the disorder of the bond angles of $\mathrm{C}$ atoms and $\mathrm{N} \mathrm{sp}{ }^{2}$ in the films [20, 22]. The width of the D peak also reflects the crystallinity of the structure: a narrower band suggests the structure is more crystalline, but if it is wider, the structure is more amorphous. For the obtained spectrum, it can be seen that peak $\mathrm{D}$ is wider, which suggests derangement of the structure due to the creation of defects, possibly through the introduction of $\mathrm{C}$ or $\mathrm{N}$ atoms between the graphite-like layers. This may indicate that the structures formed in the thin-film are more amorphous.

\subsection{SEM analysis}

The SEM images (Figure 3) acquired at different magnifications reveal the morphology of the deposited thin-film. In Figure 3(a), the carbon clusters deposited onto the $\mathrm{Cu}$ surface form a non-homogeneous surface. It is likely that this lack of uniformity is due to the distance between the electrodes $(20 \mathrm{~mm})$ because the deposition rate is proportional to this distance [23]. The agglomerations observed in the SEM image cause the formation of large islands with small grains, in turn generating an uneven surface [24]. Images of the thin-film at different magnifications, shown in Figures 3(b) and 3(c), were collected to better observe the surface. Thus, it is inferred that internal stresses decrease within the material, allowing the diffusion of particles within the film surface. This uniformity on the surface can be explained by two factors: the energy with which the plasma interacts with the target and the high internal strain generated within the samples as a result of the formation of amorphous structures
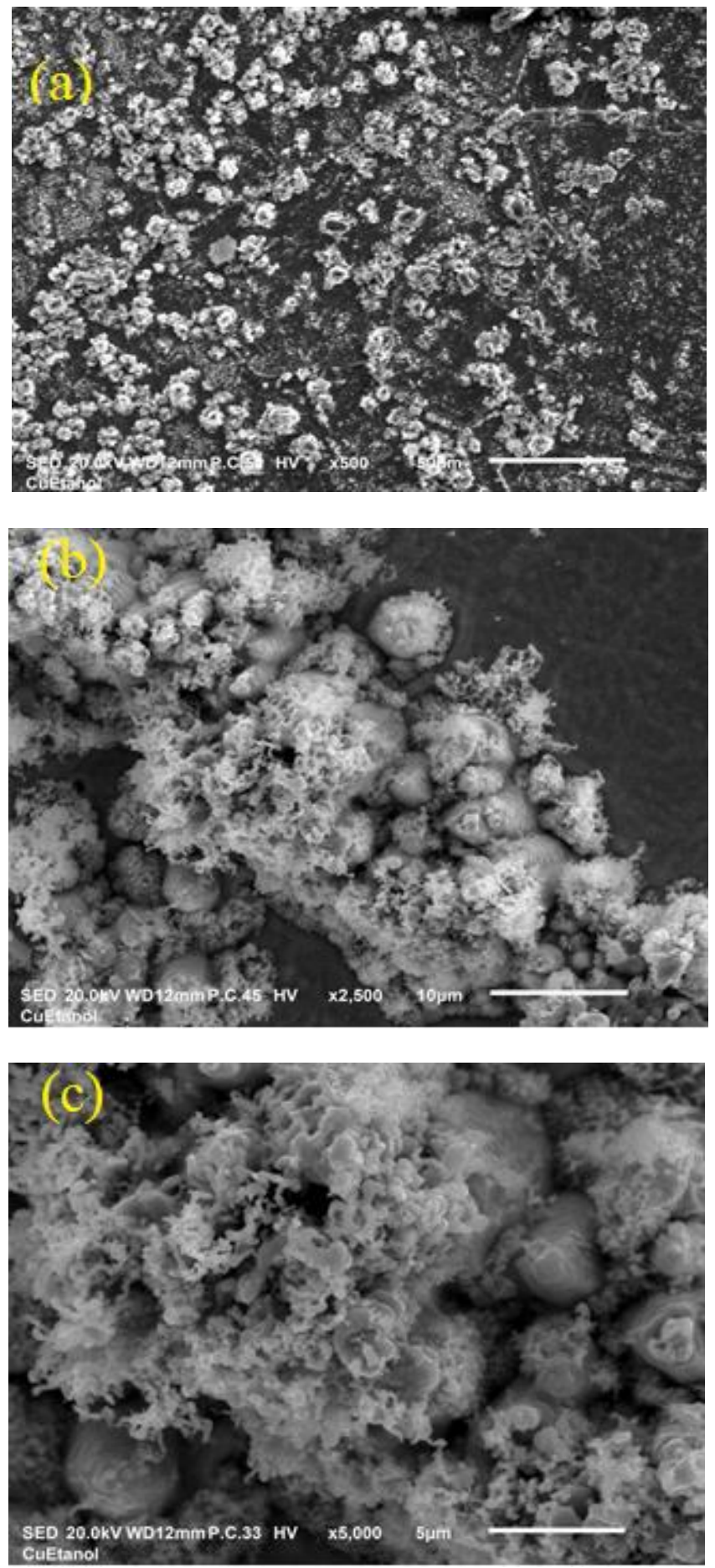

Figure 3: SEM micrographs of thin $\mathrm{CN}_{\mathrm{x}}$ deposited by pulsed discharge at a pressure of 1 Torr, taken at (a) 10X, (b) 50X, and (c) 1000X magnification. 


\subsection{AFM analysis}

Figure 4 shows the three-dimensional (3D) AFM images of the deposited thin-film using a current of $300 \mathrm{~mA}$. Figures 4(a), 4(b), and 4(c) show results obtained by AFM at different scales in contact mode that is, at swept lines of 50, 25, and $10 \mu \mathrm{m}$, respectively. The morphology that occurs in the deposited films is determined by the non-uniformity in the surface morphology, which can be explained by the presence of large graphitic domains and a polymer component of $\mathrm{CN}$.

Higher polymer components lead to a smoother film, whereas higher graphite-cluster contents and larger cluster sizes lead to more agglomerations [23]. A large polymeric component results in low roughness, whereas a greater number of graphitic clusters induce the formation of more or larger agglomerations. Although no defined grains were observed on the surfaces of the films, we have established that the $\mathrm{CN}_{\mathrm{x}}$ films had linear and graphite-like polymer components, which could lead to the surface nonuniformity. These results agree with those presented by [25] regarding the morphology of $\mathrm{CN}_{\mathrm{x}}$ films.

The microstructure, in addition to the morphology formed during thin-film formation, are important issues in determining the mechanical (hardness and elastic recovery) and tribological properties (friction coefficient and wear rate) of $\mathrm{CN}_{x}$ films [26]. Therefore, such thin films could be important materials for application in many tribological uses, because of their mechanical properties, and in solar cells, due to their optical and electrical properties [27]. Another interesting application of the present work is that the observed morphology determined the nonuniformity in the surface that effect could be reproduce using phase-field model for planer film surface [28], by the corresponding different nanoscale effects [29], or by thin planar interfacial models [30, 31].

\subsection{Plasma analysis}

Figure 5 display the OES spectrum for $\mathrm{CH}_{3} \mathrm{CH}_{2}-\mathrm{N}_{2}$ in the spectral range of 200-900 $\mathrm{nm}$. In the mixture, decomposition of $\mathrm{CH}_{3} \mathrm{CH}_{2} \mathrm{OH}$ takes place by breaking the $\mathrm{C}-\mathrm{H}$ chemical bonds in the discharge, producing atomic and molecular impacts and excitation reactions between radicals and $\mathrm{N}$ atoms. The species observed are as follows: Swan bands $\left(d^{3} \Pi_{\mathrm{g}}-a^{3} \Pi_{\mathrm{u}}\right)$, which are characteristic of the $C_{2}$ molecule at $473.71 \mathrm{~nm}(\Delta v=+1), 516.52$ $\mathrm{nm}(\Delta v=0)$, and $563.55 \mathrm{~nm}(\Delta v=-1)$ [16], and $\mathrm{CN}$ violet bands $\left(B^{2} \Sigma^{+}-X^{2} \Sigma^{+}\right)$, for which the band heads appear at $359.04 \mathrm{~nm}(\Delta v$ $=+1), 388.34 \mathrm{~nm}(\Delta v=0)$, and $421.60 \mathrm{~nm}(\Delta v=-1)$. Here $\Delta v=$ $v^{\prime}-v^{\prime \prime}$ is the difference in vibrational quantum numbers between the upper $\left(v^{\prime}\right)$ and lower $\left(v^{\prime \prime}\right)$ transition states. Also seen are $\mathrm{CH}$ $\left(B^{2} \Sigma-X^{2} \Pi\right)$ at $390 \mathrm{~nm}$ and $\mathrm{CH}\left(A^{2} \Delta-X^{2} \Pi\right)$ at $426.76 \mathrm{~nm}$.

Figure 6 shows $\mathrm{CN}, \mathrm{N}_{2}$, and $\mathrm{H}_{\beta}$ emissions observed in the plasma discharge. The $\mathrm{N}_{2}\left(B^{3} \Pi_{\mathrm{g}}-C^{3} \Pi_{\mathrm{u}}\right)$ band, which corresponds to the second positive system (SPS, $337.1 \mathrm{~nm}$ ), may be mainly due to the presence of two consecutive reactions: (1) the electron impact excitation of the $\mathrm{N}_{2}$ molecular energy ground state and (2) radiative decay to a lower level with the emission of a characteristic photon. These reactions are respectively expressed as

$$
\text { Topography - Scan forward Line fit }
$$

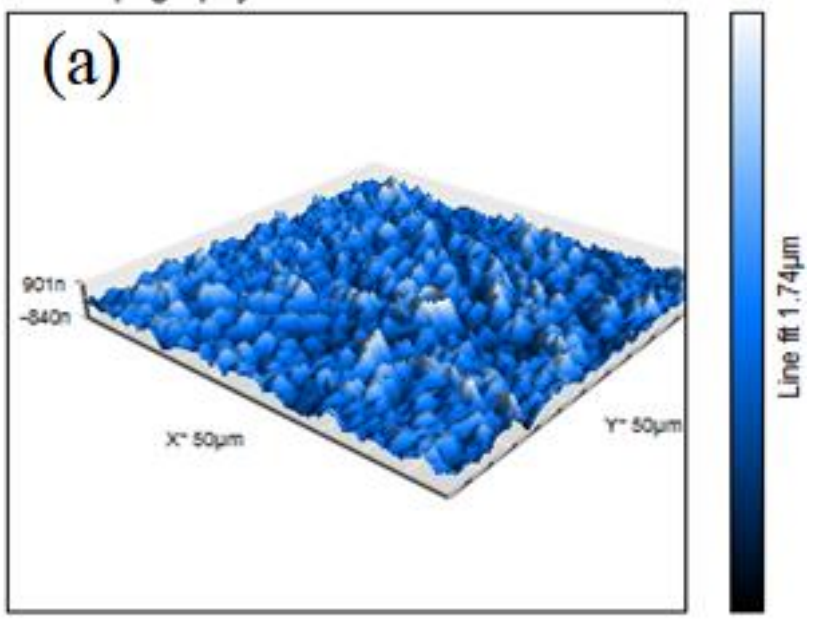

\section{Topography - Scan forward Line fit}

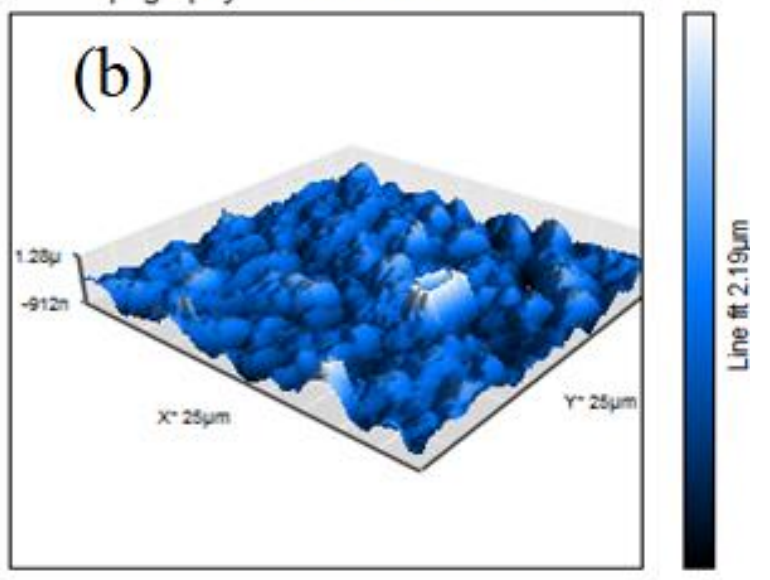

Topography - Scan forward Line fit

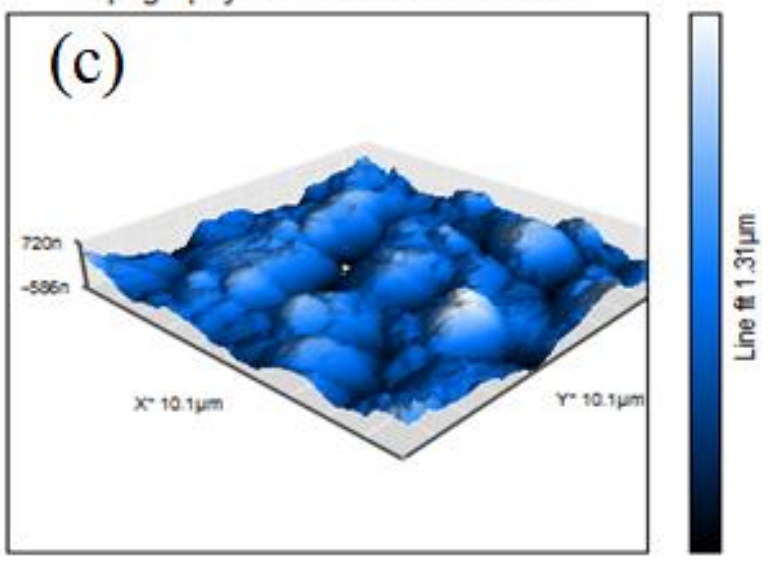

Figure 4: AFM images of thin $\mathrm{CN}_{\mathrm{x}}$ deposited by pulsed discharge at a pressure of 1 Torr, taken at different scales. (a) $50 \mu \mathrm{m}$; (b) $25 \mu \mathrm{m}$; (c) $10 \mu \mathrm{m}$

$$
e+\mathrm{N}_{2}\left(X_{1} \Sigma_{\mathrm{g}}^{+}\right) \rightarrow \mathrm{N}_{2}\left(C^{3} \Pi_{\mathrm{u}}\right)+\mathrm{e}
$$

and

$$
\mathrm{N}_{2}\left(C^{3} \Pi_{\mathrm{u}}\right) \rightarrow \mathrm{N}_{2}\left(B^{3} \Pi_{\mathrm{g}}\right)+h v(337.1 \mathrm{~nm})
$$




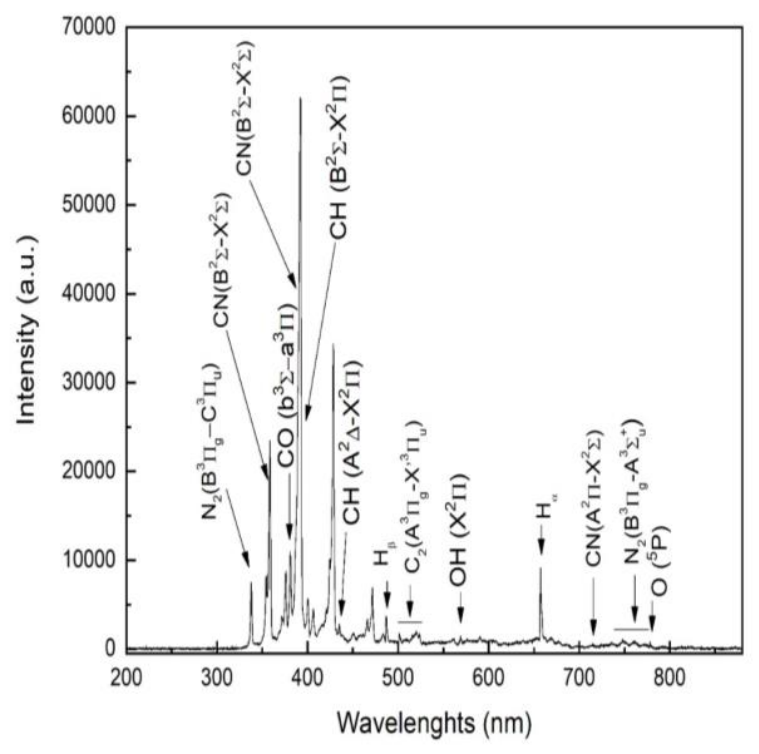

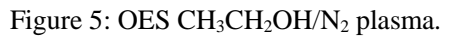

The interactions of $\mathrm{N}_{2}$ species with $\mathrm{C}_{2} \mathrm{H}_{5} \mathrm{OH}$ lead to the formation of $\mathrm{CN}$ species [32]. The violet and red spectral systems of $\mathrm{CN}$ are shown in Figure 6. The violet spectral system of $\mathrm{CN}$ may be produced by the following reaction:

$$
\mathrm{CN}\left(B^{2} \Sigma^{+}\right) \rightarrow \mathrm{CN}\left(X^{2} \Sigma^{+}\right)+h v
$$

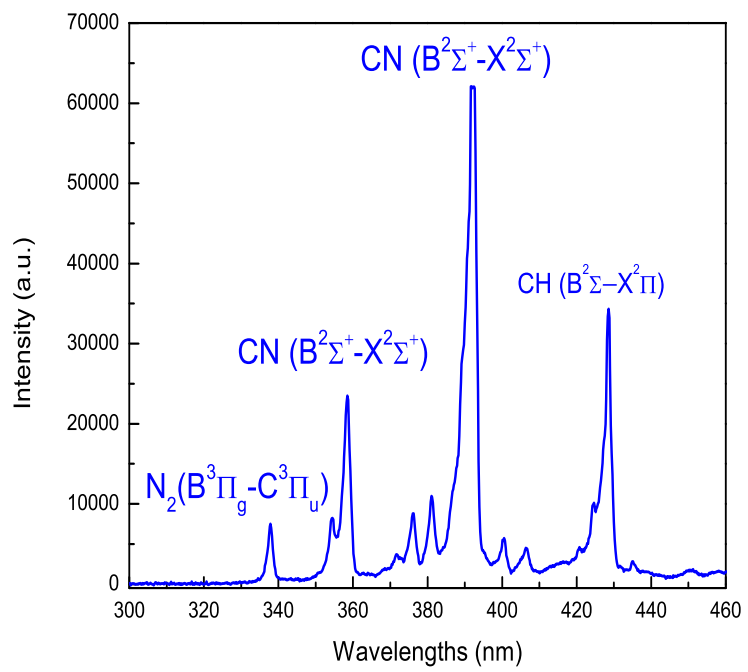

Figure 6: $\mathrm{OES}$ spectrum $\mathrm{CN}, \mathrm{N}_{2}$ and $\mathrm{CH}$ species.

which corresponds to $\Delta v=0$ and a radiative lifetime $\tau=60 \mathrm{~ns}$. The resulting vibrational distribution of $\mathrm{CN}\left(X^{2} \Sigma^{+}\right)$can be modified by relaxation processes that include vibrational collision relaxation within each electronic state, inter-electronic transfer by collision between vibrational levels of the states $X^{2} \Sigma^{+}$and $A^{2} \Pi$, and the radiative deexcitation of the vibrational levels of $A^{2} \Pi$ toward vibrational levels lower than the $X^{2} \Sigma^{+}$state. The latter of these relaxation processes result in the appearance of the red spectral system, as shown in Figure 7, and is expressed as
$\mathrm{CN}\left(A^{2} \Pi\right) \rightarrow \mathrm{CN}\left(X^{2} \Sigma^{+}\right)+h v$

with $\Delta v=3$ and a radiative lifetime $\tau=6000 \mathrm{~ns}$.

Conversely, from Figure 5 it can be seen that the $\mathrm{CN}$ species at $388.3 \mathrm{~nm}$ and the $\mathrm{N}_{2}{ }^{+}$species at $390 \mathrm{~nm}$ overlap, implying that the production of $\mathrm{CN}$ radicals in that interval is mainly linked to the excited state of $\mathrm{N}_{2}\left(C^{3} \Pi_{\mathrm{u}}\right)$. This phenomenon has two causes: (i) resonant excitation in collisions between highly excited neutral $\mathrm{N}_{2}$ molecules $(3.26 \mathrm{eV})$ and $\mathrm{CN}$ radicals $(3.19 \mathrm{eV})$ or $(i i)$ the high energy of the excited $\mathrm{N}_{2}(11.1 \mathrm{eV})$ favoring the generation of atomic $\mathrm{N}$, which in turn favors $\mathrm{CN}$ formation. The reaction of $\mathrm{N}$ atoms with $\mathrm{C}$ or $\mathrm{C}$-containing species is exothermal, which facilitates these reactions [33-35]. $\mathrm{N}$ atoms within the discharge could not be detected because their lifetimes are shortened by bonding with $\mathrm{N}$ atoms and $\mathrm{C}$-containing species.

Its peaks are also covered up by $\mathrm{CN}$ compounds with higher intensities. The presence of $\mathrm{CN}$ radicals within the discharge is mainly related to the excited state of $\mathrm{N}_{2}$ [32]. $\mathrm{C}_{2}$ Swan band emissions arise from transitions between electronic states $\left(d^{3} \Pi_{g^{-}}\right.$ $a^{3} \Pi_{u}$ ) as a probable result of the dissociation of $\mathrm{CH}_{3} \mathrm{CH}_{2} \mathrm{OH}$ in the following way:

$$
\begin{gathered}
\mathrm{CH}_{3} \mathrm{CH}_{2} \mathrm{OH} \underset{\text { e impact }}{\stackrel{\mathrm{CH}_{3} \mathrm{CH}_{2} \mathrm{OH} \rightarrow \mathrm{e}}{\longrightarrow} \mathrm{CH}_{2} \mathrm{OH}, \mathrm{CH}_{3} \underset{\text { condensation }}{\longrightarrow} \mathrm{C}(\text { solid, } \mathrm{CO})} \mathrm{CO}^{*}, \mathrm{C}_{2}^{*} \\
\text { impact }
\end{gathered}
$$

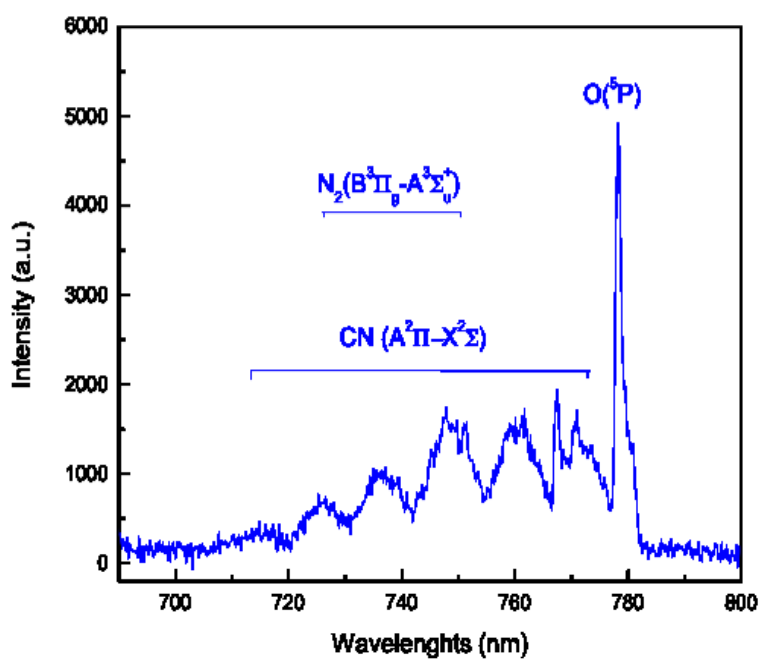

Figure 7: OES spectrum $\mathrm{CN}$ (red spectral system), $\mathrm{N}_{2}$ and $\mathrm{O}$ atom species.

As can be seen in (5), atomic hydrogen is removed from $\mathrm{CH}_{3} \mathrm{CH}_{2} \mathrm{OH}[32,36]$ and the $\mathrm{C}-\mathrm{C}$ bond finally dissociates by direct electron impact, which leads to the formation of solid carbon. The presence of $\mathrm{C}_{2}$ can be taken as an indication of solid carbon formation, as it is known that the $\mathrm{C}_{2}$ species initially nucleates in solid carbon clusters [37]. This would result in the presence of $\mathrm{C}_{2}$ Swan bands in the range of $480-530 \mathrm{~nm}$.

Swan band heads correspond to $(0,0),(1,1),(2,2),(3,3)$, and $(4,4)$ with a $\Delta v=0$. Carbon molecules react with $\mathrm{N}$ atoms in the following way:

$$
\mathrm{N}+\mathrm{C}_{2} \rightarrow \mathrm{CN}+\mathrm{C}
$$


We assume that generation of $\mathrm{C}_{2}$ molecules was caused by collisions in the plasma, which promote recombination of the dissociated $\mathrm{C}$ of the $\mathrm{CH}_{5}$ species. The $\mathrm{C}_{2}$ species and the $\mathrm{CN}$ radicals generated within the mixture contribute to the growth of the $\mathrm{CN}$ thin films. The availability of $\mathrm{C}_{2}$ species provides a considerable fraction of $\mathrm{sp}^{2}$ hybridization, as opposed to $\mathrm{sp}^{3}$ hybridization, which is an important factor in the formation of graphite-like or fullerene-like structures with $\mathrm{sp}^{2}$ hybridization in deposited $\mathrm{CN}$ films.

The emission of $\mathrm{CH}\left(B^{2} \Sigma^{+}-X^{2} \Pi\right)$ at $388.9 \mathrm{~nm}$ becomes embedded in the $\mathrm{CN}$ signal, as seen in Figure 5. The presence of $\mathrm{CH}$ in the $\mathrm{CH}_{3} \mathrm{CH}_{2} \mathrm{OH}$ discharge can be considered an indication of solid carbon and higher order hydrocarbon formation. This is because $\mathrm{CH}$ species are typically found as intermediate radicals in the formation of these products [36]. $\mathrm{CH}$ species react with nitrogen atoms in the following process:

$$
\mathrm{N}+\mathrm{CH} \rightarrow \mathrm{CN}+\mathrm{H}
$$

However, $\mathrm{CH}$ radicals can arise as intermediate reaction products to generate $\mathrm{CH}_{4}, \mathrm{C}_{2} \mathrm{H}_{2}, \mathrm{C}_{2} \mathrm{H}_{4}, \mathrm{C}_{2} \mathrm{H}_{6}$, or $\mathrm{C}_{3} \mathrm{H}_{8}[38,39]$ when hydrogen atoms $\left(\mathrm{H}_{\alpha}\right.$ and $\left.\mathrm{H}_{\beta}\right)$ react with solid carbon fragments [40-42]. The presence of $\mathrm{H}_{\alpha}$ and $\mathrm{H}_{\beta}$ in the discharge is a result of (7), which forms the hydrogen species. In Figure 5, these species are seen as the most intense lines of the Balmer series.

$$
\mathrm{e}+\mathrm{OH} \rightarrow \mathrm{O}+\mathrm{H}+\mathrm{e}
$$

The presence of $\mathrm{H}_{\alpha}$ and $\mathrm{H}_{\beta}$ is related to dissociation of the $\mathrm{CH}$ and $\mathrm{OH}$ within the discharge, as seen in (7) and (8), which could also be a new source for hydrogen generation.

\section{Conclusions}

$\mathrm{CN}_{x}$ thin films were deposited on $\mathrm{Cu}$ substrates using a pulsed discharge method with $\mathrm{CH}_{3} \mathrm{CH}_{2} \mathrm{OH}$ as the source of carbon and $\mathrm{N}_{2}$ as the sputtering ion and nitrogen source.

Through Raman analysis, it was demonstrated that the structure of the deposited films was amorphous. The characteristic Raman $D$ and $G$ peaks for carbon were identified. The position of the $G$ peak is related to the vibrational energy of the present bonds; therefore, there is a shift toward higher frequencies due to the decrease of $\mathrm{sp}^{3}$ bonds and hence the increase in $\mathrm{sp}^{2}$ bonds. This indicates that a conversion of $\mathrm{sp}^{3}$ bonds to $\mathrm{sp}^{2}$ bonds occurred in the $\mathrm{CN}_{\mathrm{x}}$ films owing to the increase in temperature. Such a conversion process could form large graphite domains with large size and/or an increased number of $\mathrm{sp}^{2}$ clusters, eventually leading to graphitization. The observed high-frequency D peak shift, on the other hand, suggested densification of ringed $\mathrm{sp}^{2}$ in the atomic network, also increasing the $\mathrm{sp}^{2}$-bond content. In addition, the Raman analysis showed an additional band centered at approximately at $2250 \mathrm{~cm}^{-1}$, which appears because of the stretching vibration of a triple bond $\mathrm{C}-\mathrm{N}$. This suggests that the $\mathrm{C}$ and $\mathrm{N}$ atoms are chemically bonded in the film. An $I_{D} / I_{G}$ value of 1.32 suggested that $\mathrm{C} \mathrm{sp}$ is more likely to have formed in the film, considering that $\mathrm{C}=\mathrm{C}$ and/or $\mathrm{C}=\mathrm{N}$ bonds can be formed in rings and there are fewer opportunities to form $\mathrm{C}=\mathrm{C}$ and/or $\mathrm{C}=\mathrm{N}$ links in chains. In addition, this $I_{D} / I_{G}$ value indicated the growth of the graphitic domains or the increase of their number, i.e., graphitization by heating with an increase in disorder of the angles of the bonds of the $\mathrm{C}$ and $\mathrm{N}$ atoms $\mathrm{sp}^{2}$ in the films.

Through SEM analysis, we were able to observe the thin-film morphology, wherein carbon clusters deposited on the surface of the $\mathrm{Cu}$ were observed. The lack of uniformity of the nonhomogeneous surface can be attributed to the distance between the electrodes during the deposition process. Since the deposition rate is considered proportional to the distance, these observed agglomerations cause the formation of large islands with small grains, in turn generating an irregular surface. These results were later corroborated with AFM results, from which we determined the morphology of the $\mathrm{CN}_{x}$ film. The surface was found to lack uniformity, which can be explained by the presence of large graphite domains and a polymeric component of $\mathrm{CN}$. This reveals that the greater the content of graphite groups or the larger their size, the greater the number of agglomerations. Finally, we conclude that the films grow via island growth, very similar to the results presented by [25].

OES measurements confirmed the decomposition of the $\mathrm{CH}_{3} \mathrm{CH}_{2} \mathrm{OH}$ molecule as a result of electron impact dissociation in the plasma discharge. Products obtained from the dissociation collide with the $\mathrm{N}$ species to generate $\mathrm{CN}$ radicals and form violet and red emission spectra characteristic of $\mathrm{CN}$. $\mathrm{CN}$ radicals are important because of their variety of industrial applications, mainly in materials science. In addition, the $\mathrm{C}_{2}$ Swan band, a species that also plays an important role in the appearance of $\mathrm{CN}$ radicals, was identified. The presence of $\mathrm{CH}$ indicated the formation of solid carbon. Hydrogen species were also detected in the $\mathrm{CH}_{3} \mathrm{CH}_{2} \mathrm{OH}-\mathrm{N}_{2}$ plasma mixture. Therefore, the mixture plasma is not only useful for producing $\mathrm{CN}$ but also for generating hydrogen.

\section{Conflict of Interest}

The authors declare no conflict of interest.

\section{Acknowledgment}

We are grateful to the Advanced Physics Laboratory (FC/UAEM), Spectroscopy laboratory (ICF/UNAM) and TESJo for their infrastructure provided to carry out the research. This research was supported by CONACyT scholarship for doctoral study, DGAPA[IN102222], CONACyT [225991 and 268644] and UAEM [4307/2017/CI].

\section{Reference}

[1] M. Uz A. Y. Liu, M. L. Cohen, (1992), Theorical study of a hypothetical metallic phase of carbon, Phys. Rev. B, 45, 4579-4581. https://doi.org/10.1103/PhysRevB.45.

[2] Y. Bu, Z. Chen, J. Yu \& W. Li, (2013), A novel application of $g-\mathrm{C}_{3} \mathrm{~N}_{4}$ thin film in photo-electrochemical anticorrosion, Electrochim. Acta., 88, 294-300. https://doi.org/10.1016/j.electacta.2012.10.049

[3] S. Yan, C., Li, Z. S. \& Zou, Z. G., (2009), Photo-degradation Performance of $\mathrm{g}-\mathrm{C}_{3} \mathrm{~N}_{4}$ Fabricated by Directly Heating Melamine, Langmuir, 25, 1039710401. https://doi.org/10.1021/la900923z

[4] F. K. Kessler; Y. Zheng; D. Schwarz; C. Merschjann; W. Schnick; X. Wang; M. J. Bojdys, (2017), Functional carbon nitride materials- design strategies for electrochemical devices, Nature Reviews Materials, 17030. https://doi.org/10.1038/natrevmats.2017.30

[5] K. Schwinghammer, M. B. Mesch, V. Duppel, C. Ziegler, J. Senker and B V. Lotsch, (2014), Crystalline Carbon Nitride Nanosheets for Improved 
Visible-Light Hydrogen Evolution, J. Am.Chem.Soc.,136, 5, 1730-1733. https://doi.org/10.1021/ja411321s

[6] J. Xu, M. Antonietti, and M. Shalom, (2016), Moving Graphitic Carbon Nitride from Electro-catalysis and Photo-catalysis to a Potential Electrode Material for Photoelectric Devices, Chem. Asian J., 11, 2499-2512. https://doi.org/10.1002/asia.201600857

[7] R. Kour, Sandeep Arya, Sheng-Joue Young, Vinay Gupta, Pankaj Bandhoria, and Ajit Khosla, (2020), Review-Recent Advances in Carbon Nanomaterials as Electrochemical Biosensors, Journal of The Electrochemical Society, 167 037555. https://doi.orfg/10.1149/1945-7111/ab6bc4

[8] H. Yu, P. Li, J. Robertson, (2011), Fabrication and bio-functionalization of tetrahedral amorphous carbon thin films for bio sensor applications, Diamond \& Related Materials, 20, 1020-1025. https://dx.doi.org/10.1016/j.diamond.2011.06.005

[9] Z. A. Umar, R. S. Rawat, R. Ahmad, Z. Chen, Z. Zhang, J. Siddiqui, A. Hussnain, T. Hussainc and M. A. Baiga, (2017), Structural, compositional and hardness properties of hydrogenated amorphous carbon nitride thin films synthesized by dense plasma focus device, Surface and Interface Analysis, 49, 548-553. https://doi.org/10.1002/sia.6192

[10] P. Wang, T. Takeno, K. Adachi, H. Miki \& T. Takagi, (2012), Preparation and tribological characterization of amorphous carbon nitride coatings in a RF PECCVD-DC PVD hybrid coating process, Applied Surface Science, 258, 6576-6582. https://doi.org/10.1016/j.apsusc.2012.03.082

[11] D, Nicolas et al., Thierry Fouquet, Patrick Choquet, (2015), Atmospheric Pressure Plasma Initiated Chemical Vapor Deposition Using Ultra-Short Square Pulse Dielectric Barrier Discharge, Plasma Process. Polym., 12, 6674. https://doi.org/10.1002/ppap.201400094

[12] N. Nedfors, Oleksiy Vozniy, and Johanna Rosen, (2018), Effect of synchronized bias in the deposition of $\mathrm{TiB}_{2}$ thin films using high power impulse magnetron sputtering, J. Vac. Sci. Technol. A, 36, 3. https://doi.org/10.116/1.5003194

[13] A. Aijaz Kostas Sarakinos, Mohsin Raza, Jens Jensen and Ulf Helmersson, Principles for designing sputtering-based strategies for high-rate synthesis of dense and hard hydrogenated amorphous carbon thin films, Diamond and Related Materials. Vac., 44, 117-122, 2014. https://doi.org/10.1016/j.diamond.2014.02.014

[14] Y. Kang, Yongqiang Yang, Li-Chang Yin, Xiangdong Kang, Gang Liu, and Hui-Ming Cheng, (2015), An Amorphous Carbon Nitride Photo-catalyst with Greatly Extended Visible-Light-Responsive Range for Photo-catalytic Hydrogen Generation, Adv. Mater., 27, $4572-4577$. https://doi.org/10.1002/adma.201501939

[15] R O Dillon, J Woollam, V Katkanant, (1984), Use of Raman scattering to investigate disorder and crystallite formation in as-deposited and annealed $\begin{array}{lllll}\text { carbon films, } & \text { Phys. Rev. B, }\end{array}$ https://doi.org/10.1103/PhysRevB.29.3482

[16] Y Taki, T Kitagawa, O Takai, (1997), Shielded arc ion plating and structural characterization of amorphous carbon nitride thin films, Thin Solid Films, 304, 183-190. https://doi.org/10.1016/S0040-6090(97)00193-4

[17] A C Ferrari, S E Rodil, J Robertson, (2003), Interpretation of infrared and Raman spectra of amorphous carbon nitride, Phys. Rev. B, 67, 155306, 155. https://doi.org/10.1103/PhysRevB.67.155306

[18] H Jung, H Ho Park, (2000), Studies on the structure and bonding state of nitric amorphous carbon $\left(\mathrm{a}-\mathrm{CN}_{\mathrm{x}}\right)$ films by reactive rf magnetron sputtering, Thin Solid Films, 377-378, 320-325. https://doi.org/10.1016/S00406090(00)01363-8

[19] J. Wang, N. Huang, C. J. Pan, S.C.H. Kwok, P. Yang, Y.X. Leng, J. Y. Chen, H. Sun, G. J. Wan, Z. Y. Liu and P. K. Chu, (2004), Bacterial repellence from polyethylene terephthalate surface modified by acetylene plasma immersion ion implantation-deposition, Surface and Coatings Technology, 186 (1-2), 299-304. https://doi.org/10.1016/j.surfcoat.2004.02.046

[20] E. Cappelli, C. Scilletta, S. Orlando, V. Valentini and M. Servidori., (2009), Laser annealing of amorphous carbon films, Applied Surface Science, 255, 5620-5625. https://doi.org/10.1016/j.apsusc.2008.10.062

[21] L. Marcinauskas, A. Grigonis, P. Valatkevicius and A. Medvid, (2012), Irradiation of the graphite-like carbon films by ns-laser pulse, Applied Surface Science, 261 488-492. https://doi.org/10.1016/j.apsusc.2012.08.042

[22] X. Wang, Z. Li, P. Wu, E. Jiang and H. Bai, (2006), Annealing effects on the microstructure of amorphous carbon nitride films, Applied Surface Science, 253 (4), 2087-2092. https://doi.org/10.1016/j.apsusc.2006.04.003

[23] R. Maeda \& K. Kikuch, (1997), Deposition of thin films by uv light laser ablation, Surf. Eng., 13,71-74. https://doi.org/10.1179/sur.1997.13.1.71

[24] Ming Gao, Danni Liu, Huanhuan Yang, Hao Huang, Qian Luo, Yifan Huang, Xue-Feng Yu and Paul K.Chu, (2019), Modification of Layered Graphitic Carbon Nitride by Nitrogen Plasma for Improved Electrocatalytic Hydrogen
Evolution, Nanomaterials, 9, 568. https://doi.org/10.3390/nano9040568

[25] A. Stanishevsky, (1998), On the surface morphology of C: N films deposited by pulsed cahodic arc discharge method, Mater. Lett., 37, 162-167. https://doi.org/10.1016/S0167-577X(98)00085-8

[26] E. Broitman et al., Mechanical and tribological properties of $\mathrm{CN}_{\mathrm{x}}$ films deposited by reactive magnetron sputtering, Wear, 248, 55-64. https://doi.org/10.1016/S00431648(00)00519-6

[27] Z. B. Zhoua, R. Q. Cui, Q. J. Pang, G. M. Hadi, Z. M. Ding, W. Y. Li, (2002), Schottky solar cell with amorphous carbon nitride thin films prepared by ion sputtering technique, Solar Energy Materials \& Solar Cell, 70, 487-493. https://doi.org/10.1016/S0927-0248(01)00086-1

[28] A. M. Roy, (2021), Barrierless melt nucleation at solid-solid interface in energetic nitramine octahydro-1, 3, 5, 7-tetrazocine, Materialia, 15, 101000. https://doi.org/10.1016/j.mtla.2021.101000

[29] A. M. Roy, (2021), Influence of Nanoscale Parameters on Solid-Solid Phase Transformation in Octagen Crystal: Multiple Solution and Temperature Effects, JETP Letters, $113 \quad$ (4), 265-272. doi.org/10.1134/S0021364021040032

[30] A. M. Roy, (2021), Formation and stability of nanosized, undercooled propagating intermediate melt during $\beta \rightarrow \delta$ phase transformation in HMX nanocrystal, Europhysics Letters, 133, 56001. doi: 10.1209/0295$5075 / 133 / 56001$

[31] A. M. Roy, (2021), Energetics and kinematics of undercooled nonequilibrium interfacial molten layer in cyclotetramethylenetetranitramine crystal, Physica B: Condensed Matter, 615, 412986. https://doi.org/10.1016/j.physb.2021.412986

[32] E. Tatarova, N. Bundaleska, F. M Dias, D. Tsyganov, R. Saavedra and C. M. Ferreira, (2013), Hydrogen production from alcohol reforming in a microwave 'tornado'-type plasma, Plasma Sources Sci. Technol., 22. 065001. https://doi.org/10.1088/0963-0252/22/6/065001

[33] K. J. Clay, S. P. Speakman, G. A. J. Amaratunga, and S. R. P. Silva, (1996), Characterization of a-C:H:N deposition from $\mathrm{CH}_{4} / \mathrm{N}_{2}$ rf plasmas using optical emission spectroscopy, J. Appl. Phys., 79 (9),7227-7233. https://doi.org/10.1063/1.361439

[34] S. Veprek, J. Weidmann and F. Glatz, (1995), Plasma chemical vapor deposition and properties of hard $\mathrm{C}_{3} \mathrm{~N}_{4}$ thin films, J. Vac. Sci. Thechnol., 13, 2914. https://doi.org/10.1116/1.579613

[35] Wei Hu, Jun-Yi Tang, Jia-da Wu, Jian Sun, Yi-qun Shen, Xiao-feng Xu, and Ning $\mathrm{Xu}$, (2008), Characterization of carbon nitride deposition from $\mathrm{CH}_{4} / \mathrm{N}_{2}$ glow discharge plasma beams using optical emission spectroscopy, Physics of plasma, 15, 073502. https://doi.org/10.1063/1.2953521

[36] A. Yanguas-Gil, J. L. Hueso, J. Cotrino, A. Caballero, and A. R. GonzálezElipe, (2004), Reforming of ethanol in a microwave surface-wave plasma discharge, Appl. Phys. Lett., 85,4004-4006. https://doi.org/10.1063/1.1808875

[37] A. Kumar, P. A., A. Xue, B. Hao , Y. K. Yap and R. M. Sankaran, (2013), Formation of nanodiamonds at near-ambient conditions via micro-plasma dissociation of ethanol vapour, Nature Communication, 4, 2618. https://doi.org/10.1038/ncomms3618

[38] J. Serrano, J. Moros and J. J. Laserna, (2015), Exploring the formation routes of diatomic hydrogenated radicals using femtosecond laser-induced breakdown spectroscopy of deuterated molecular solids, J. Anal. At. Spectrom., 30, 2343-2352. https://doi.org/10.1039/C5JA00192G

[39] G. M. Harris and A. W. Tickner, (1947), Reaction of Hydrogen Atoms with Solid Carbon, Nature, 160,871 . https://doi.org/10.1038/160871a0

[40] A. Okita, Y. Suda, A. Ozeki, H. Sugawara, Y. Sakai, A. Oda, and J. Nakamura, (2006), Predicting the amount of carbon in carbon nanotubes grown by $\mathrm{CH}_{4} \quad \mathrm{RF}$ plasmas, J. Appl. Phys., 99, 014302. https://doi.org/10.1063/1.2150599

[41] A. Okita, Y. Suda, A. Oda, J. Nakamura, A. Ozeki, K. Bhattacharyya, H Sugawara, and Y. Sakai, (2007), Effects of hydrogen on carbon nanotube formation in $\mathrm{CH}_{4} / \mathrm{H}_{2}$ plasma, Carbon, 45, 7, 1518-1526. https://doi.org/10.1016/j.carbon.2007.03.022

[42] A. Oda, Y. Suda, and A. Okita, (2008), Numerical analysis of pressure dependence of carbon nanotube growth in $\mathrm{CH}_{4} / \mathrm{H}_{2}$, Thin Solid Films, 516, 19, 6570-6574. https://doi.org/10.1016/j.tsf.2007.11.088 